\title{
CONTRADIÇÕES NO DISCURSO E NA PRÁTICA DO TRABALHO DE ENFERMAGEM NOS SERVIÇOS-DIA DE SAÚDE MENTAL
}

\author{
CONTRADICTIONS IN SPEECH AND PRACTICE OF NURSING IN DAY-CARE \\ MENTAL HEALTH SERVICES
}

\section{CONTRADICCIONES EN LO DISCURSO E EN LA PRACTICA DEL TRABAJO DE ENFERMERIA EN LOS SERVICIOS-DIA EN SALUD MENTAL}

Débora Isane Ratner Kirschbaum * Flora Karina Correa de Paula**

Kirschbaum DIR, Paula FKC. Contradições no discurso e na prática do trabalho de enfermagem nos serviços-dia de saúde mental. Rev Esc Enferm USP 2002; 36(2): 170-6.

\section{RESUMO}

Atualmente, observa-se que os enfermeiros ainda não consolidaram uma nova identidade profissional na maioria das instituições de saúde mental, comprometidas com a implementação da Reforma Psiquiátrica. Por isso, o presente artigo tem por objetivo caracterizar o trabalho de enfermagem realizado em dois serviços-dia do municipio de Campinas-SP, por meio de um estudo exploratório e descritivo de natureza qualitativa. Depreende-se da análise dos dados que as atividades de enfermagem visam principalmente as necessidades de cuidado dos clientes relacionadas ao campo da Reabilitação Psicossocial, embora sua implementação apresente certas contradições que evocam a presença de traços compativeis com o modelo assistencial anterior.

PALAVRAS-CHAVE: Psiquiatria. Enfermagem Psiquiátrica. Serviços de Saúde Mental. \begin{abstract}
It has been observed nowadays that nurses have not yet consolidated a new professional identity in the majority of mental health institutions compromised with the implementation of Psychiatric Reform. Therefore, the objective of this work is to characterize the nursing care provided in two day —care institutions located in the city of Campinas-SP through an exploratory descriptive study of qualitative nature. The data analysis show that nursing activities concern mostly in fulfilling the client's needs related to the field of Psicho-social Reabilitation. Nevertheless, its implementation displays some contradictions wich evoke the presence of traces compatible with the former model of assistance.
\end{abstract}

KEYWORDS: Psychiatry. Psychiatric Nursing. Mental Health Services.

\section{RESUMEN}

En Brasil se obserba que la nueva identidad profesional de los enfermeros no esta consolidada en la mayoria de las instituiciónes de salud mental comprometidas com la implementación de la Reforma Psiquiátrica. El presente estudio tiene como objetivo caracterizar el trabajo de enfermeria en dos servicios de dia del municipio de Campinas-SP Es una investigación exploratoria e descriptiva de naturaleza cualitativa. La análisis nos permitió verificar que las actividades de enfermería tienen por objectivo las necesidades de cuidado del enfermo relacionadas con el paradigma de la Rehabilitación Psicosocial, aunque la implementación exponga contradicciones más compatibles con el modelo manicomial.

PALABRAS-CLAVE: Psiquiatria. Enfermeria Psiquiátrica. Servicios de Salud Mental.

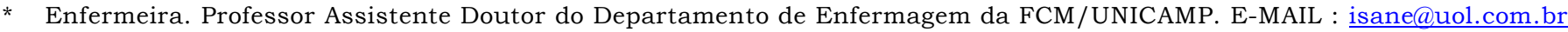

** Aluna do $7 \mathrm{Q}$ semestre do Curso de Graduação em Enfermagem da FCM/UNICAMP. Bolsista do PIBIC-CNPq.

E-mail: flora1979@hotmail.com 


\section{INTRODUÇÃO}

Na década de 80, o Movimento de Reforma Psiquiátrica chega ao país, a exemplo do que vinha ocorrendo desde a Segunda Guerra Mundial na Europa e América do Norte, e daí decorre uma nova discussão sobre a necessidade de mudança na atuação da enfermagem e outros profissionais da área.

Atualmente, vários trabalhos apontam (1-3) que os enfermeiros, na maioria das instituições de saúde mental não consolidaram uma nova identidade profissional, refletindo, na realidade, uma indefinição no próprio modelo de intervenção dos serviços, que estão construindo seu funcionamento de modo fundamentado nos preceitos da Reforma Psiquiátrica, mas influenciados também por experiências empíricas desenvolvidas no seu próprio serviço ou em outros, descritos na literatura. $\mathrm{O}$ ensino de enfermagem psiquiátrica, na maioria das escolas, não foi profundamente reformulado, segundo ROCHA (2), o que tende a dificultar a inserção e a adequação dos agentes de enfermagem ao novo paradigma das politicas atuais de saúde mental no país.

Neste novo modelo assistencial substitutivo ao manicomial, o trabalho de enfermagem (4) poderia ser caracterizado por ter como objeto de ação a recuperação de autonomia dos pacientes com graves transtornos psiquiátricos, com o objetivo de reestabelecer sua capacidade de gerir sua vida. Logo, a finalidade da prática de enfermagem é reinserir socialmente os usuários, dos quais, grande parte foi submetida a longos períodos de internação e isolamento social e, por fim, como tecnologia para se atingir o que se almeja (reinserção social) criou-se ou reformulou-se toda uma rede de serviços comunitários, que aliados às ações terapêuticas que devem ser desenvolvidas por profissionais de saúde mental, possibilitariam reabilitar os sujeitos à vida comunitária. Entretanto, não há um modelo estabelecido para atuação de enfermagem, que depende, muitas vezes, da forma como é organizado o processo de trabalho da instituição em que atua. Além disso, uma mudança no discurso não significa sempre uma mudança nas práticas, que foram historicamente determinadas e que são dificeis de serem reformuladas a curto prazo, já que o ensino de enfermagem psiquiátrica nas escolas, mesmo após a implantação da Reforma Psiquiátrica, pouco mudou (2).

Deste modo, viu-se a necessidade de caracterizar o trabalho de enfermagem em serviços-dia, que são equipamentos tidos como novos dentre os serviços da rede de atenção ao doente mental.
Ao estudar os hospitais-dia paulistas, Campos $^{\circ}$ descreve-os como equipamentos alternativos à "hospitalização integral, ou combinada a ela, reduzindo o tempo de internação; como continuação imediata da internação integral, numa transição gradual para a comunidade; como complemento do tratamento ambulatorial; ou como programa de reabilitação para pacientes que requerem cuidados intensivos", atendendo, segundo Zusman apud Campos (3) "a mesma população que as unidades de regime integral".

Observa-se uma expansão significativa do número de serviços-dia nos anos 90, dentre os quais ressaltam-se os Hospitais-dia (HDs) e os Centros de Atenção Psicossocial (CAPS), assim como uma importante articulação destes equipamentos em torno do ideário da Reabilitação Psicossocial(5).

A Reabilitação Psicossocial, enquanto modelo tecnoassistencial*, toma como objetivo a reinserção social do doente mental, através de uma rede de serviços comunitários, nos quais são desenvolvidas ações de diversos profissionais para este fim.

O paradigma da Reabilitação Psicossocial emergiu como núcleo do movimento de Reforma Psiquiátrica, que vem sendo implantado no país desde a década de 80 e que é conceituado por Silva apud Campos (3) como "um conjunto de ações que passam pela revisão das politicas de saúde mental e dos modelos de assistência; da base ideológica do estatuto que regulamenta a existência do ser humano que utiliza o serviço de saúde mental, público ou privado e, consequentemente, pela adoção de um novo código de ética que este final de século impõe à humanidade, pois não cabe mais aprisionar humanos no, final do século $X X$ dentro de códigos morais do século passado", cujo objetivo seria reformular a atenção psiquiátrica, substituindo os meios de tratamento existentes no país, como os manicômios por espaços extra-hospitalares.(3)

Neste novo modelo, as ações são desenvolvidas no intuito de favorecer a competência social dos doentes mentais a fim de estimular o desempenho de atividades cotidianas compativeis com a vivência comunitária.

Vale lembrar que a terapêutica utilizada anteriormente determinava grandes períodos de internação hospitalar em manicômios, com práticas custodiais, que só estimulavam o isolamento dos "loucos" e grande parcela da população submetida a este tratamento é hoje alvo dos programas de Reabilitação Psicossocial.

\footnotetext{
* Segundo Merhy $\left({ }^{6}\right)$, um modelo deve ser capaz de "descrever explicitamente qual seu problema de saúde, quais são suas práticas, para que servem e como devem ser organizados enquanto serviços, além de explicitar quem são seus trabalhadores e seus usuários". (p.26)
} 
A Reforma Psiquiátrica também prevê reformulações na equipe de atendimento do doente mental, onde retira-se o foco da figura do profissional médico, que era o personagem central da psiquiatria no modelo médico-clínico(4) e emergem outros profissionais, com distintas formações, que também atenderão o doente mental.

Os profissionais, nestas experiências abandonam a identidade profissional e, refere CAMPOS ${ }^{(7)}$, se tornam competentes promotores da saúde, entretanto perdem a capacidade de executar procedimentos típicos de cada especialidade.

Uma forma de minimizar este problema, encontrada nos dois serviços, é determinar, com clareza qual será o Núcleo de Competência e o Núcleo de Responsabilidade dos profissionais.

O autor citado anteriormente define o Núcleo de Competência como o "conjunto de saberes $e$ de responsabilidades específicos a cada profissão $e$ especialidade", marcando a distinção dos profissionais com diferentes formações numa equipe(7). Continuando, ele afirma que o Campo de Competência e Responsabilidade refere-se "aos saberes $e$ responsabilidades comuns ou confluentes às várias profissões e especialidades"(7)

Como expõe Campos(7), mesmo em trabalho multiprofissionais, define-se as responsabilidades individuais de cada profissional. Ainda para este autor, estes conceitos "permitiriam certa abertura no paradoxo da autonomia e definição de responsabilidade. "(7)

Disso decorre a necessidade de caracterizar os novos contornos que o trabalho de enfermagem possivelmente adquiriria nestes serviços, tendo em vista a ampliação e a transformação de seu objeto de trabalho, que teria as necessidades de cuidado do cliente como parâmetro para a sua realização.

Esta caracterização do trabalho de enfermagem tem como objetivo geral verificar qual a relação entre as mudanças no modelo assistencial nos equipamentos após o início da Reforma Psiquiátrica e o trabalho de enfermagem necessário à implementação do cuidado nos serviços de hospitalização parcial (serviços-dia); e como objetivos específicos: (I) caracterizar o trabalho de enfermagem voltado para às necessidades de cuidado; (II) analisar historicamente as práticas de enfermagem em serviços-dia após a Reforma Psiquiátrica, no intuito de se compreender de que forma se constituiu o saber de enfermagem empregado hoje nos diferentes serviços e que permeia as atuais atribuições dos enfermeiros nessas instituições.

\section{METODOLOGIA DE PESQUISA}

A presente pesquisa é uma investigação de cunho qualitativo-decritivo, que utilizou a observação participante e entrevistas não diretivas com roteiro semi-estruturado como instrumentos. A coleta de dados foi realizada em dois serviços-dia do município de Campinas, que pertencem a uma só instituição, o Serviço de Saúde Dr. Cândido Ferreira (SSCF). Trata-se do Hospital-Dia (HD) e Centro de Atenção Psicossocial (CAPS) da referida instituição.

O Hospital-Dia foi inaugurado em março de 1991, funcionando de segunda às sexta-feira, das 08:00 às 18:00hrs, com capacidade para atender até 110 pacientes.

Constitui-se um serviço intermediário entre os hospitais e a rede básica de atendimento, sendo um local de transição entre a internação integral e a rede básica.

Os usuários têm diferentes diagnósticos, tais como; abuso de droga lícitas e ilícitas, psicoses e neuroses graves, estão numa faixa etária de 15-65 anos e frequentam a instituição por um ou mais dias da semana, conforme a necessidade. Chegam à instituição por encaminhamento de outros serviços ou por procura espontânea.

O CAPS fica fora da área física do Cândido Ferreira, localizado no bairro Botafogo, próximo ao centro de Campinas.

Sua clientela compõe-se de indivíduos com "transtorno mental grave, residentes no distritos norte e sul de Campinas, encaminhados pelas Unidades Básicas de Saúde. Também compõem sua clientela parte dos usuários das moradias extrahospitalares do SSCF, egressos da antiga Unidade de Reabilitação de Moradores "(fonte: Diretrizes Operacionais do Centro de Atenção Psicossocial).

Cada uma destas unidades tem um gerente que coordena as atividades da equipe, um grupo de técnicos, como são denominados os profissionais de nível superior e uma equipe de auxiliares de enfermagem.

A observação foi realizada por cinco dias no HD e seis dias no CAPS, onde se acompanhou o trabalho de profissionais de enfermagem que foram posteriormente entrevistados. A observação permitiu à pesquisadora apreender como eram organizados os dois serviços, bem como propiciou uma aproximação com os sujeitos da pesquisa. A população de estudo foi composta por uma enfermeira e quatro auxiliares de enfermagem, que concordaram em ceder seus depoimentos, gravados em fita k-7. Foi-lhes garantido que sua identidade seria mantida em sigilo e a realização da pesquisa foi aprovada pelo Colegiado da instituição pesquisada. 
Os dados coletados foram posteriormente agrupados em categorias e submetidos à análise de conteúdo, conforme proposta por Minayo (8). Embasouse a discussão em conceitos oriundos da Reabilitação Psicossocial.

\section{RESULTÃDOS E DISCUSSÃO}

Embora a clientela seja composta por pacientes que apresentam diferentes categorias diagnósticas, especialmente no hospital-dia, consequentemente com diferentes quadros clínicos e distintas necessidades de cuidado, o foco de ação da enfermagem está nos pacientes psicóticos, especialmente os esquizofrênicos, já que, durante o período de observação, constatou-se que estes pacientes compõem o maior grupo de usuários, permanecem o maior tempo na instituição e necessitam de maior número de cuidados e intervenções, devido a dificuldade que estes pacientes têm em desempenhar atividades cotidianas.

O prognóstico da esquizofrenia sempre foi considerado sombrio, já que se trata de uma morbidade definhante, com aspecto demencial. Entretanto, Saraceno ${ }^{(9)}$ refere que estudos epidemiológicos, iniciados em psiquiatria há vinte anos, trouxeram a incerteza de que a evolução da esquizofrenia e psicoses não-orgânicas fosse "naturalmente desfavorável" (9), o que levaria à "cronicidade e à internação", já que algumas pesquisas nesta área demonstram otimismo em relação ao curso e prognóstico desta doença.

Saraceno (9) sugere que a "cronificarão $e$ o empobrecimento (em sentido amplo) do psicótico são resultados não necessariamente intrínsecos à doença, mas a uma constelação de variáveis que podem ser modificadas e orientadas no processo de intervenção". Estas variáveis, são geralmente ligadas a contextos "microssociais" (família e comunidade) e pressupões estratégias de "manejo ambiental, que se encontram distantes das estratégias comuns propostas pelo modelo psiquiátrico biomédico ".

Bandeira ${ }^{(10)}$ acredita que a dificuldade do paciente em desempenhar as atividades sociais advém de sintomas psiquiátricos e do efeito secundário dos medicamentos, e estas dificuldades são potencializadas com os longos períodos de internação psiquiátrica, ao qual grande parte destes pacientes foi submetida.

Para a mesma autora, com o intuito de facilitar e estimular a interação social do esquizofrênico, são necessários "fatores de proteção", tais como "medicação, intervenções terapêuticas junto à família do paciente e o treinamento de habilidades instrumentais e sociais" e a intervenção terapêutica tem como objetivos fundamentais o "ensino de habilidades sociais que torna o paciente mais preparado para lidar com situações de conflito interpessoal" e também "habilidades instrumentais cotidianas" para o convivio social(10)

\section{Atividades assistenciais desenvolvidas pelos auxiliares}

Passa-se agora a analisar de que modo essas construções teóricas foram sendo reelaboradas e assimiladas à prática concreta do trabalho dos agentes de enfermagem a partir da descrição das atividades desempenhadas por estes trabalhadores. Para tanto, apresenta-se inicialmente as atividades assistenciais relativas ao auto-cuidado e, após, as de estímulo às atividades de vida diária, as de promoção da comunicação, ações técnicas de enfermagem, ações classificadas como acompanhamento terapêutico e, por fim, o desenvolvimento de grupos.

\section{Auto-cuidado :}

- Higienização do paciente: as auxiliares de enfermagem do HD encaminham o paciente ao banho, oferecendo-lhes o material necessário, permanecendo com eles no banheiro somente se consideram que o paciente não tem condições de tomar banho sozinho. O trecho a seguir comprova a afirmação.

\section{" (...) cuida da higiene do paciente, do banho, de uma roupa limpa, de cortar uma unha, essas coisas..." El}

Não há critérios definidos em consenso e descritos para avaliação da autonomia do paciente no banho. Isto é baseado na avaliação empírica, construída no cotidiano do trabalho das auxiliares. Também não foi descrito que tipo de acompanhamento as auxiliares fazem no banho do paciente, se- somente observam ou se responsabilizam inteiramente pela higiene.

A falta de ênfase nos critérios, que não foram sequer citados pelas auxiliares de enfermagem, pode levar a pensar que, na verdade, estes não foram estabelecidos por estas profissionais, que mais uma vez, baseariam sua atuação em conhecimentos nãoestruturados.

Sabe-se que qualquer intervenção com o doente mental deve ter uma finalidade, e que as atividades oferecidas aos clientes como, por exemplo, o banho, devem visar a máxima autonomia possível do usuário em relação aos profissionais. Logo, os auxiliares deveriam estimular a independência do paciente e avaliar a real necessidade acompanhá-lo nesta atividade, sendo mais importante, na realidade, propiciar as condições para que os pacientes quem tenham maior autonomia, por exemplo, convidandoos a organizar o material que necessitam, a escolher as poupas que usarão, a temperatura da água com relação ao clima. Se não forem garantidas estas condições, não há nenhuma diferença qualitativa entre o modo como o banho é realizado no modelo atual, 
como forma do paciente recuperar habilidades relativas às atividades de vida diárias e o sentido por vezes dado ao banho no modelo assistencial manicomial, ou seja, com intuito apenas de promover a higiene, sem qualquer conotação terapêutica.

- Medicação: os pacientes são ensinados a tomar a medicação prescrita, e quando apresentam alguma dificuldade, passam por um treinamento, no qual freqüentemente se orienta o uso da medicação. No HD, os usuários que não conseguem tomá-la sozinhos recebem-na no próprio serviço, exceto aos finais de semana, quando o paciente leva a medicação para casa e procura-se orientar algum familiar, quando possivel. Os usuários do CAPS, em sua grande maioria residentes nas moradias extra-hospitalares do Serviço de Saúde Dr. Cândido Ferreira, contam com a visita de uma auxiliar de enfermagem que passa diariamente nas casas (no horário prescrito para administração dos medicamentos, nos períodos da manhã, tarde, noite ou nos três horários) e que administra os remédios aos moradores que não conseguem cuidar da sua medicação. Na Casa Primavera, residência terapêutica sediada no interior das instalações do Serviço de Saúde Dr. Cândido Ferreira, onde habita um grupo de moradores com baixa autonomia e que freqüenta diariamente o CAPS, a auxiliar de enfermagem também é responsável por administrar a medicação, em esquema similar ao do HD.

Os auxiliares são responsáveis por detectar qualquer falha na medicação: dosagem errada, medicação alterada (é comum, segundo relatam as auxiliares, que uns pacientes tomem medicação de outros, quando não há supervisão), o não uso da mesma, bem como avaliar os efeitos da terapêutica medicamentosa proposta (ouve-se os auxiliares comentando com técnicos que "tal medicação não está adequada em fulano", porque "parece que ele está piorando...").

Este item demonstra a importância do trabalho das auxiliares, já que a medicação dos pacientes é uma condição decisiva para evitar piora e crises, com subsequentes internações hospitalares, que poderiam ser evitadas, diminuindo-se os fatores que levam ao isolamento e não dificultam a interação social do doente(10).

\section{Estímulo às atividades de vida diária:}

- Transporte: As auxiliares de enfermagem do HD durante muito tempo foram responsáveis por ensinar os usuários deste serviço a utilizar transporte público para chegar ao $\mathrm{HD}$ ou retornar à casa. Atualmente, esta atividade é desenvolvida pelas monitoras de terapia ocupacional.

- Alimentação: Havia no HD, (há projeto de implantação no CAPS), um grupo de culinária cujo objetivo, além de entreter os usuários, é ensinar os pacientes a cozinhar, para que eles possam cuidar da própria refeição. Os depoimentos abaixo ilustram isto:

"Agora tá parado a culinária, mas tinha um grupo de culinária também". (El)

\section{" (...) faz de tudo: acompanha o paciente para almoço, se precisa..." (E1)}

Além de entreter os usuários com o grupo de culinária, melhora-se o convívio social deles, já que são estimulados a compartilhar os mesmos utensílios e materiais e fazem as refeições preparadas juntos.

Além disso, nas moradias extra-hospitalares, os próprios moradores fazem as compras de mantimentos, a referência da casa (no caso a enfermeira), acompanha os moradores na ida ao supermercado, avaliando a necessidade de auxiliá-los. Numa das casas, a própria moradora encarregada de ir ao supermercado faz a lista de compras e procura os alimentos no supermercado. Em outra moradia, os pacientes são mais dependentes e a enfermeira se encarrega de verificar o que eles estão precisando comprar.

- Higiene das casas: As moradias são limpas uma vez por semana por um funcionário da limpeza do SSOF, o resto dos dias, os moradores são orientados a realizar a limpeza da casa, lavar as roupas, etc. Notase que em uma das casas visitadas a limpeza era bem feita pelos moradores e na outra, os pacientes, classificados por E3, como com menor grau de autonomia, não limpavam adequadamente o local.

Quando os técnicos ou auxiliares detectam que a limpeza da casa não está adequada, chamam um profissional da limpeza do Serviço de Saúde Dr. Cândido Ferreira para arrumar o local e tentam, na medida do possivel, problematizar a questão, no sentido de verificar porque houve a falha da limpeza e estimular os moradores a determinar responsabilidades, como definir quem lava a louça, dentre outras.

\section{Ações técnicas de enfermagem;}

Nesta categoria inclui-se o controle da medicação dos pacientes (aqueles que não têm autonomia para assumirem a medicação sozinhos, conforme exposto anteriormente) e outros procedimentos técnicos que são atribuídos à enfermagem, tal como coleta de exames, conforme se depreende dos depoimentos abaixo:

"eu administro a medicação da tarde que ele tem que tomar". (E4)

"Ah! a gente dá medicação, faz coleta de exames (...)" (El)

\section{Acompanhamento terapêutico:}

Algumas tarefas são classificadas pelas próprias auxiliares de enfermagem como de "acompanhamento 
terapêutico", que são aquelas atividades desenvolvidas com o usuário durante o período de permanência na instituição na própria instituição ou em locais diferentes. Classificam-se nesta categoria as atividades como caminhadas, passeios, encontros (como exemplo o churrasco de natal promovido pelo HD, como o dinheiro arrecadado na venda dos bordados feitos pelas pacientes), ver televisão, conforme exposto nos trechos a seguir;

\section{" (...)faz passeios, caminhadas, às vezes vai eu, às vezes vai E2, né?" (El)}

"(...) vou estar indo a um cinema com um usuário que estiver frequentando aqui, vou estar indo com ele no shopping para ele tomar um sorvete, fazendo um "A.T." com ele, entendeu?" (E4)

$\mathrm{Na}$ realidade o sentido de acompanhamento terapêutico é mais amplo e diferenciado do descrito pelos entrevistados. E definido por Braga Filho" como "companhia de ação", onde, a "relação é fundada na atividade, na ação...marcada pelo afeto que subjaz à transmissão e à construção compartilhada de um conhecimento"(p. 154). Para realizar um acompanhamento terapêutico, são necessários diálogo e conversação, e tal autor acredita que isso pode ser conseguido pela companhia de ação, ou seja, desenvolver atividades em parceria com os sujeitos.

Segundo uma orientação psicanalitica, a palavra assume suma importância por permitir ao sujeito expressar um entendimento e marcar reconhecimentos pela palavra vinda de outros, deste modo o objetivo do acompanhamento terapêutico seria "pesquisar uma ação que conduz a um saber que possibilite uma fala". 11)

Portanto, a rigor, o trabalho que as auxiliares de enfermagem desenvolvem não poderia ser considerado como um acompanhamento terapêutico, dentro de uma orientação psicanalitica, pois não incluem na sua realização um certo grau de formulação teórica para poder significar o que o sujeito expressa pela fala.

\section{Atividades que estimulam a comunicação do usuário:}

Conforme descrito, um dos objetivos dos programas de Reabilitação Psicossocial é melhorar as formas de expressão do usuário. Atividades como desenho e pintura desempenham a função de melhora da comunicação por concentrar num mesmo ambiente várias pessoas com um objetivo comum (de pintar ou desenhar) e compartilhando o mesmo material, além disto, os pacientes são estimulados a explicar os desenhos feitos e isto pode promover uma melhor articulação das palavras utilizadas, uma vez que os pacientes esforçam-se para serem compreendidos.
Outra referência que as profissionais fazem a esta categoria seria a receptividade à diálogos com pacientes. Muitas vezes, os pacientes procuram as auxiliares de enfermagem para contar-lhes o que estão pensando, sentindo ou mesmo para conversar coisas cotidianas, conforme constatado no período de observação e exemplificado no depoimento abaixo:

" Conversa, né? Com o paciente, eles procuram muito, assim, prá conversar..." (El)

Vê-se que, conforme apontado por alguns autores ${ }^{(2,12)}$ pelas características de seu trabalho, o auxiliar fica bastante exposto a este contato em que o paciente traz diversas questões de sua vida pessoal, seus conflitos, seus temores, dentre outros. Deste modo, a nosso ver, a instituição deveria se responsabilizar por instrumentalizar melhor os auxiliares, para que estes tenham maiores recursos ao lidar com esta demanda.

Ou seja, será que sua formação the possibilitaria acolher e dar um encaminhamento que gerasse efeitos terapêuticos a esses conteúdos que são trazidos pelo paciente nestas conversas? Quais seriam os recursos que lhe possibilitariam capacitar-se para isso ?

\section{Grupos}

Os grupos conduzidos pelas auxiliares de enfermagem são realizados com diferentes objetivos, e contribuem para que o paciente adquira alguma habilidade. Como exemplo, temos no HD o grupo de café, onde os usuários aprendem a fazer café; o grupo de bordado, neste grupo, as pacientes têm oportunidade de aprender bordados simples em guardanapos, que são posteriormente vendidos e o dinheiro arrecadado é utilizado para alguma atividade escolhida pelas pacientes; grupo de culinária. No CAPS há o projeto de fazer atividades em grupo (desenho, culinária), mas no período de observação ainda não tinham sido implantadas estas atividades.

As auxiliares de enfermagem também participam de grupos conduzidos por técnicos, tais como grupo de alcoolistas, de drogaditos, mas na observação realizada no grupo de alcoolistas do HD (com um médico psiquiatra e uma auxiliar de enfermagem) não foi observada uma participação efetiva destas trabalhadoras.

\section{CONSIDERAÇÕES FINAIS}

A enfermagem desempenha tarefas adequadas às descritas na literatura como necessárias à reabilitação social do psicótico, entretanto realiza estas tarefas de forma não sistematizada, não planejada, o que seria um problema para se atingir a qualidade desejável dos programas de reabilitação psicossocial. 
A ausência de educação formal que contemple os tópicos de reabilitação psicossocial em saúde mental é um dos principais impedimentos para haver uma estruturação no saber de enfermagem aplicado à prática cotidiana nas instituições analisadas.

Pode-se verificar, ao final desta investigação, uma situação que evoca algumas considerações já feitas anteriormente por outros autores que também procuraram apreender o que caracterizava o trabalho de enfermagem e suas transformações em meio à Reestruturação da Atenção Psiquiátrica no país. Na primeira metade dos anos 90, Rocha (2) detectou a formação ineficiente, afirmando que a assistência da equipe auxiliar é construída empiricamente, "oriundo da experiência de vida, pessoal e profissional" (2), e considera que os auxiliares não sabem a "ciência" (p.121) que há em seu trabalho, ficando na dependência do saber de outros profissionais para realizar assistência.

Conforme afirma Cerqueira apud Rocha(2) "se quisermos operar mudanças na assistência ao doente mental, teremos que oferecer um bom preparo aos profissionais de enfermagem" (2).

Rocha() acredita que o caminho para que os profissionais de enfermagem melhorem sua atuação está em desenvolver atividades de "vivência", a fim de promover "auto-conhecimento e conhecimento do outro, bem como reflexão sistematizada".(2)

Outro modo de promover a reflexão do trabalho do grupo e auxiliares de enfermagem, seria promover supervisão clínica (que conforme descrição de Vasconcelos ${ }^{(13)}$, compreende a avaliação de casos e condutas e o estudo da teoria) de forma mais intensa, já que no CAPS e no HD os profissionais de enfermagem têm acesso à discussão de casos, mas não de forma intensiva.

Acredita-se que com um espaço aberto à discussão e troca de experiências entre o grupo de auxiliares, com a retaguarda de um técnico da equipe, que preste informações e compartilhe conhecimentos, seria um bom momento de avaliação de condutas e esclarecimento de questões que dificultam o funcionamento do grupo, como certas questões administrativas (padronização de formas de se registrar as observações referentes à evolução do usuário, por exemplo).

Esta opinião é partilhada pela enfermeira entrevistada, que acredita que os auxiliares têm que ter seu trabalho valorizado, para que possam compreender a importância de seus cuidados, e deste modo, adquirir o hábito de reflexão sistematizada, a fim de verificar se suas condutas estão sendo compativeis com a demanda de atenção expressa pelo usuário.

\section{REFERÊNCIAS BIBLIOGRÁFICAS}

(1) Kirschbaum DIR. As possibilidades de integração ensinoserviço. In Anais do $4^{\circ}$ Ciclo de Debates em Enfermagem Psiquiátrica 1998 Belo Horizonte. Belo Horizonte, Centro de Extensão da Escola de Enfermagem da UFMG, 1999. p. 29-44.

(2)Rocha RM. Enfermagem psiquiátrica: que papel é este? Rio de Janeiro:Instituto Franco Basaglia/Editora TeCorá;1994.

(3) Campos CMS. Consolidando a Reforma Psiquiátrica no Brasil através dos Hospitais-Dia: a emergência das contradições entre a intencionalidade e a operacionalidade. (Dissertação) São Paulo(SP) Escola de Enfermagem daUniversidade de São Paulo;1998

(4) Almeida MCP, Rocha SMM. organizadores O trabalho de enfermagem. São Paulo: Cortez,1997.

(5) Delgado PG, Venancio AT, Leal E. organizadores O Campo da Atenção Psicossocial. In: Anais do I Congresso de Saúde Mental do Estado do Rio de Janeiro, 1997. Rio de Janeiro: Instituto Franco Basaglia. Editora Te Corá, 1997.

(6) Merhy EE. A saúde pública como politica: um estudo sobre reformuladores de políticas. São Paulo: Hucitec; 1992.

(7) Campos GWS. Subjetividade e administração de pessoal: considerações sobre modos de gerenciar o trabalho em equipes de saúde. In: Mehry E; Onocko R organizadores. Agir em saúde: um desafio para o público. São Paulo: Hucitec; 1997.

(8) Minayo CS. O desafio do conhecimento: pesquisa qualitativa em saúde. 3.ed.São Paulo: Rio de Janeiro. Hucitec-Abrasco; 1994.

(9) Saraceno B. Libertando Identidades. Rio de Janeiro: RelumeDumará; 1999.

(10) Bandeira M. Competência Social de Psicóticos: parâmetros do treinamento para programas de reabilitação psicossocial - parte I. J Bras Psiq. 1999; 48(3):95-195.

(11) Braga Filho LG. Acompanhamento Terapêutico: esboço de articulação de uma terapêutica profana. Rev Terap Ocup USP. $1991 ; 2(4): 146-156$

(12) Kirschbaum DIR. A trajetória da enfermagem psiquiátrica no Brasil, no periodo compreendido entre as décadas de 50 a 90. Campinas: 1997. (Projeto de Pesquisa apresentado à Unicamp)

(13) Vasconcelos EM. Desintitucionalização e interdisciplinaridade em saúde mental. In:Cadernos IPUB. Saúde Mental e desinstitucionalização: reinventando serviços. Rio de Janeiro:Instituto de Psiquiatria da UFRJ. 1997

\section{Artigo recebido em 15/09/00}

Artigo aprovado em 27/09/02 